\title{
The Near-Death Experience: Knowledge and Attitudes of College Students
}

\author{
Kay E. Ketzenberger, Ph.D. \\ Gina L. Keim, B.A. \\ University of Texas of the Permian Basin
}

\begin{abstract}
There is a considerable literature documenting the effects of a near-death experience (NDE) on persons who actually undergo the experience, in terms of their attitudes and opinions about NDEs. However, investigations of how much nonexperiencers know about NDEs and their attitudes towards them are in short supply. This study examined the relationship in people who have not had an NDE between attitudes toward and knowledge of near-death experiences. Subjects were undergraduate students, with a mean age of 32 years. The Near-Death Phenomena Knowledge and Attitudes Questionnaire was employed to assess attitudes toward and knowledge of NDEs. Results indicated that both knowledge and attitudes were relatively normally distributed, and that level of knowledge significantly predicted attitudes towards NDEs, accounting for 34 percent of the common variance.
\end{abstract}

KEY WORDS: knowledge of near-death experiences; attitudes to near-death experiences.

Since ancient times it has been recognized that people who experience a brush with death sometimes report profound and unusual phenomena. Raymond Moody (1975) labeled this complex collection of subjective changes the near-death experience (NDE). In the early $1970 \mathrm{~s}$, Elisabeth Kübler-Ross began a public discussion about the existence of near-death phenomena, doing more to arouse public acceptance and curiosity about NDEs than any other single figure (Walker and Serdahely,

Kay E. Ketzenberger, Ph.D., is Assistant Professor of Psychology, and Gina L. Keim, B.A., was at the time of this research an undergraduate student in the Department of Behavioral Science, University of Texas of the Permian Basin. Reprint requests should be addressed to Dr. Ketzenberger at the Department of Behavioral Science, University of Texas of the Permian Basin, 4901 East University Boulevard, Odessa, TX 79762; e-mail: ketzen_k@utpb.edu. 
1990). There is no universally recognized definition for the NDE, nor is there agreement on whether it is best viewed as one complex and multifaceted state or as several distinct entities (Roberts and Owen, 1988).

Several investigators have attempted a preliminary classification of NDEs. Kenneth Ring (1980) interviewed 102 patients who had come close to death, concluding that there is a "core" near-death experience that evolves in a characteristic pattern, with earlier stages reported more frequently than later ones: (1) an experience of peace, well-being, and absence of pain; (2) a sense of detachment from the physical body, progressing to an out-of-body experience (OBE); (3) entering darkness, a tunnel experience with panoramic memory and predominantly positive affect; (4) an experience of bright, warm, attractive light; and (5) entering the light, meeting persons or figures.

Moody (1975) emphasized that no two NDEs are identical, all the above elements are not necessarily present, and the sequence of stages may vary. Ring (1980) agreed that most people do not experience all five stages. Bruce Greyson (1985) categorized NDEs into discrete types, indentifying transcendental, paranormal, affective, and cognitive components. One of the most frequently reported aftereffects of NDEs is a reduced fear of death and a more favorable life outlook (Flynn, 1982; Moody, 1975; Ring, 1980), although a small number of persons have reported terrifying NDEs (Greyson and Bush, 1992).

Public testimonies regarding near-death experiences have become increasingly prevalent during the 20 th century. Whether because of better life-saving techniques, increased lifespans, or more frequent and candid disclosures, NDEs are relatively common today (Walker and Serdahely, 1990). Thousands of case studies have documented NDEs, particularly over the past 25 years. According to a Gallup Poll, 5 percent of the adult population report having gone through a near-death experience (Gallup and Proctor, 1982), an estimated eight million persons.

We cannot reliably answer, however, the question of how the NDE phenomenon has been received by the population at large. Surveys of numerous professional groups, including physicians, nurses, psychologists, and members of the clergy and other selected communities have investigated subject knowledge, acceptance, and understanding of NDEs (Moore, 1994; Orne, 1986; Royse, 1985; Walker and Russell, 1989). These surveys suggested that the effects of information about NDEs include comfort, hope, and inspiration. In a survey of primarily male religious clergy, David Royse (1985) found attitudes to be positive and generally supportive of people who have undergone a near-death experience. An Australian survey showed that women, younger persons, 
and those who professed a belief in life after death were more likely to react positively to the NDE (Kellehear and Heaven, 1989).

For all the work that has been done on the effects of NDEs (Flynn, 1986; Grey, 1985; Ring, 1980, 1984), there has been little published regarding how nonexperiencers (nonNDErs) are influenced by their exposure to information about NDEs. The lack of research on this topic is surprising considering the many historical reports about NDEs and the immense publicity from the mass media on the topic. Most of the population have not had an NDE. That we know so little about how most people respond to the NDE-based material now available to the general public is a notable deficit in the field of near-death studies (Ring, 1995).

Recent research has begun to explore this question. Ring (1992; Ring and Rosing, 1990) compared the beliefs and values of a control group of subjects, who were interested in NDEs but had never experienced one themselves, to those of NDErs. Results showed that the control group, after becoming interested in NDEs, exhibited many of the same positive effects as the NDErs, though to a lesser degree. Controls tended to show the same value profiles as NDErs as well (Ring, 1995). Investigating the - impact of NDEs on subjects who have not experienced one themselves, Ring (1995) found that nonNDErs who took a course on the near-death experience expressed feelings, values, and beliefs that were practically identical to those commonly expressed by NDErs. While the NDErs attributed their attitudes to having undergone a near-death experience, the nonNDErs reportedly derived the same effects simply from exposure to the NDE course.

Research to date has been based primarily on samples who have had a near-death experience; it is limited for those who have not had an NDE. Also, there is little mention of the general relationship between level of knowledge about NDEs and attitudes towards them. The current study was conducted to investigate whether a relationship exists between public knowledge of and attitudes towards the near-death experience.

\section{Method}

\section{Subjects}

The sample consisted of 50 undergraduate students (27 women and 23 men) enrolled in the University of Texas of the Permian Basin. All stated they had not had a near-death experience. Demographic 
information was collected on gender, age, race, religious preference, marital status, and whether or not the student was acquainted with anyone who had undergone an NDE. Subject age ranged from 19 to 53 , with a mean of 32 years $(S D=9.6$ years). Thirty-nine subjects (78 percent) were Caucasian, with the remaining 11 (22 percent) being Hispanic. Twenty-nine subjects (58 percent) were married, 14 (28 percent) single, and the remaining 7 (14 percent) reported being either divorced or separated. Thirty-three subjects ( 66 percent) described their religious preference as Protestant, seven (14 percent) as Roman Catholic, four (8 percent) as "other," and six (12 percent) as "none." Fourteen participants ( 28 percent) reported knowing someone who had experienced an NDE.

\section{Instrument}

The Near-Death Phenomena Knowledge and Attitudes Questionnaire (Thornburg, 1988), which assesses attitudes and knowledge about NDEs, was modified for use with this subject pool. The word "student" was substituted for "physician" or "nurse," "people" for "patients," and items based on the study subject being a health care provider or possessing medical knowledge were omitted. The instrument yields a knowledge score and an attitude score. The knowledge component consists of 16 true/false/undecided items; scores range from 0 to 16 , with higher scores indicating greater knowledge. The attitude component consists of 165 -point Likert scale items ranging from "strongly agree" to "strongly disagree;" scores range from 16 to 80 , with higher scores signifying more positive attitudes. No normative scores were available.

\section{Results}

Knowledge scores ranged from 3 to 14 , with a mean of $8.9(\mathrm{SD}=2.3)$; attitude scores ranged from 17 to 75 , with a mean of $43.1(\mathrm{SD}=15.4)$. Both knowledge and attitude scores were relatively normally distributed; knowledge scores had a slight negative skew, while attitude scores were slightly skewed in the positive direction.

Knowledge and attitudes were highly correlated $(r=.583, p<.001)$, and regression analysis revealed that knowledge was significantly predictive of attitudes $(F=25.04, \mathrm{df}=1,48 ; p<.001)$; thus, as knowledge about NDEs increased, attitudes were more positive. This relationship accounted for 34.3 percent of the shared variance between knowledge 
and attitudes. Analysis of the demographic variables revealed no significant effects for age, gender, race, religious preference, marital status, or being acquainted with an NDEr.

\section{Discussion}

This study was the first to establish that knowledge and attitude scores are relatively normally distributed. Though no normative scores were available against which to compare, these results at least provide a starting point for future comparisons. Our data support results of previous studies that found no significant association between common demographic variables and knowledge of or attitudes towards NDEs (Gallup and Proctor, 1982; Ring, 1980, 1984). It remains possible, however, that the sample was too small to identify small effect sizes for these factors.

These results are meaningful in that they offer evidence that knowledge about the near-death experience, in and of itself, is significantly related to the attitudes people hold. The fact that knowledge and attitudes share 34 percent common variance is noteworthy, particularly in social science research where correlations, even when significant, are generally rather small. As a largely correlational study, the data cannot identify causation. Though it remains possible that increased knowledge leads to more positive attitudes, it is equally possible that more positive attitudes lead to increased interest in NDEs and a seeking out of more knowledge about them.

It should also be noted that a subject sample composed entirely of college students may well differ from the general population in important respects, most obviously in age and education. Although the students' mean age of 32 is more similar to the general population than to traditional students populations of 18 to 22 years of age, the educational difference remains a concern for generalizability to non-student populations. Interpretation of these results should, therefore, be limited to the college student population, though for both traditional and nontraditionally aged students.

The etiology of this correlation between knowledge and attitudes could have important ramifications for those interested in attitude change. If the relationship is simple and direct, increasing knowledge by whatever means could lead to improvements. However, if knowledge is a mediating variable between attitudes and interest, then attitude change efforts would most profitably be aimed at piquing public interest in the subject. 


\section{References}

Flynn, C. P. (1982). Meanings and implications of near-death experiencer transformations: Some preliminary findings and implications. Anabiosis: The Journal of NearDeath Studies, 2, 3-14.

Flynn, C. P. (1986). After the beyond: Human transformation and the near-death experience. Englewood Cliffs, NJ: Prentice-Hall.

Gallup, G., and Proctor, W. (1982). Adventures in immortality: A look beyond the threshold of death. New York, NY: McGraw-Hill.

Grey, M. (1985). Return from death: An exploration of the near-death experience. London, England: Arkana.

Greyson, B. (1985). A typology of near-death experiences. American Journal of Psychiatry, $142,967-969$.

Greyson, B., and Bush, N. E. (1992). Distressing near-death experiences. Psychiatry, 55 , 95-110.

Kellehear, A., and Heaven, P. (1989). Community attitudes towards near-death experiences: An Australian study. Journal of Near-Death Studies, 7, 165-177.

Moody, R. A. (1975). Life after life. Covington, GA: Mockingbird Books.

Moore, L. H. (1994). An assessment of physicians' knowledge of and attitudes toward the near-death experience. Journal of Near-Death Studies, 13, 91-102.

Orne, R. M. (1986). Nurses' view of NDEs. American Journal of Nursing, 86, 417-420.

Ring, K. (1980). Life at death: A scientific investigation of the near-death experience. New York, NY: Coward, McCann, and Geoghegan.

Ring, K. (1984). Heading toward omega: In search of the meaning of the near-death experience. New York: William Morrow.

Ring, K. (1992). The Omega Project: Near-death experiences, UFO encounters, and mind at large. New York: William Morrow.

Ring, K. (1995). The impact of near-death experiences on persons who have not had them: A report of a preliminary study and two replications. Journal of Near-Death Studies, $13,223-235$.

Ring, K. and Rosing, C. J. (1990). The Omega Project: An empirical study of the NDEprone personality. Journal of Near-Death Studies, 8, 211-239.

Roberts, G., and Owen, J. (1988). The near-death experience. British Journal of Psychiatry, 153, 607-617.

Royse, D. (1985). The near-death experience: A survey of clergy's attitudes and knowledge. Journal of Pastoral Care, 39, 31-42.

Sabom, M. B. (1982). Recollections of Death: A medical investigation. New York, NY: Harper and Row.

Thornburg, N. (1988). Development of the Near-Death Phenomena Knowledge and Attitudes Questionnaire. Journal of Near-Death Studies, 6, 223-238.

Walker, B. A., and Russell, R. D. (1989). Assessing psychologists' knowledge and attitudes toward near-death phenomena. Journal of Near-Death Studies, 8, 103-110.

Walker, B. A., and Serdahely, W. J. (1990). Historical perspectives on near-death phenomena. Journal of Near-Death Studies, 9, 105-121. 